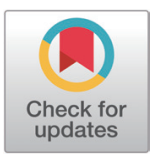

Received: Apr 5, 2021

Revised: May 8, 2021

Accepted: May 24, 2021

*Corresponding author

Eunsuk Cho

Swine Science Division, National Institute of Animal Science, Rural

Development Administration, Cheonan 31000, Korea.

Tel: +82-41-580-3457

E-mail: segi0486@korea.kr

Joeun Kim

Swine Science Division, National Institute of Animal Science, Rural Development Administration, Cheonan 31000 , Korea

Tel: +82-41-580-3454

E-mail: kjektw@korea.kr

Copyright $(2021$ Korean Society of Animal Sciences and Technology. This is an Open Access article distributed under the terms of the Creative Commons Attribution Non-Commercial License (http:// creativecommons.org/licenses/by$\mathrm{nc} / 4.0 /$ ) which permits unrestricted non-commercial use, distribution, and reproduction in any medium, provided the original work is properly cited.

ORCID

Yongdae Jeong

https://orcid.org/0000-0002-1985-583X Yohan Choi

https://orcid.org/0000-0003-4710-4731

Doowan Kim

https://orcid.org/0000-0003-2392-5535

\section{Effects of cooling systems on physiological responses and intestinal microflora in early gestating sows exposed to high- temperature stress}

\author{
Yongdae Jeong, Yohan Choi, Doowan Kim, Yejin Min, Eunsuk Cho* and \\ Joeun Kim*
}

Swine Science Division, National Institute of Animal Science, Rural Development Administration, Cheonan 31000, Korea

\section{Abstract}

This study was conducted to investigate the effect of cooling systems on reproductive performance, body temperature, blood metabolites, and the intestinal microbiome in early gestating sows exposed to high ambient temperature. In total, 39 pregnant sows (Landrace $\times$ Yorkshire; 2 parities) were randomly assigned to and maintained in the following three treatment groups ( 13 sows per group) over days 0 to 35 of pregnancy: (i) air cooling (AC; $26.87 \pm 1.23^{\circ} \mathrm{C}$ ), (ii) water-drip cooling (WC; $28.81 \pm 0.91^{\circ} \mathrm{C}$ ), and (iii) a lack of cooling with heat stress (HS; $30.72 \pm 0.70^{\circ} \mathrm{C}$ ). Backfat thickness was measured before and after HS. Feces were collected on day 0 and $35 \mathrm{~d}$ of the trial for microbiome analysis, whereas blood was taken at day 35 of pregnancy and analyzed. Reproductive performance and physiological responses were identified at day 35 . Respiration rate along with rectal and skin temperatures were lower ( $p$ $<0.05$ ) in the AC group than in the HS and WC groups. Serum blood urea nitrogen values were increased $(p<0.05)$ in the WC group compared with those measured in the AC and HS groups. Triiodothyronine was found at greater levels $(p<0.05)$ in the AC than in the HS group. Reproductive performance was not affected by the cooling systems. At the phylum level, fecal pathogenic Spirochaete and Euryarchaeota were found in higher numbers ( $p$ $<0.05$ ) in all groups after HS. Similarly, at the genus level, the amount of Treponema was greater $(p<0.05)$ in all groups after HS. In conclusion, our results suggest that AC or WC can ameliorate or mitigate the adverse effects of HS on the physiological parameters of pregnant sows reared under high temperatures.

Keywords: Heat stress, Gut microbiome, Thyroid hormone, Gestating sows

\section{INTRODUCTION}

Increased temperatures and heat waves due to the changing climate have negatively affected the animal industry [1,2]. In such conditions, livestock can suffer heat stress (HS) that may severely reduce carcass 
Yejin Min

https://orcid.org/0000-0002-3083-1513

Eunsuk Cho

https://orcid.org/0000-0001-5223-099X

Joeun Kim

https://orcid.org/0000-0002-1935-2132

\section{Competing interests}

No potential conflict of interest relevant to this article was reported.

Funding sources

This work was carried out with the support of "Cooperative Research Program for Agriculture Science and Technology

Development (Project No. PJ014796)" Rural Development Administration, Republic of

Korea and supported by the Bio \& Medical Technology Development program of the National Research Foundation of Korea (NRF) funded by the Ministry of Science and ICT (MSIT) of Korea (Project No. 2019M3A9F3066121).

\section{Acknowledgements}

This study was supported by 2021 the RDA

Fellowship Program of National Institute

of Animal Science, Rural Development

Administration, Korea.

Availability of data and material

Upon reasonable request, the datasets

of this study can be available from the

corresponding authors.

\section{Authors' contributions}

Conceptualization: Jeong Y, Kim J.

Data curation: Jeong Y, Choi Y, Min Y.

Formal analysis: Choi Y, Kim D.

Methodology: Kim D.

Software: Cho E.

Validation: Choi Y

Investigation: Jeong Y, Kim D.

Writing - original draft: Jeong $Y$

Writing - review \& editing: Cho E, Kim J.

Ethics approval and consent to participate This study was approved by IACUC of Rural Development Administration (No. NIAS2019-7131). quality via reduced lean growth and increased fat content $[3,4]$. The HS reduces the growth rate of livestock by lowering feed intake and it causes an imbalance in physiological responses such as blood metabolic indicators, respiration rate, nutrient metabolism, and rectal temperature [5]. Consequently, HS can induce enormous economic loss, which is increasing annually with global warming [1].

Swine are susceptible to HS because of their naturally nonfunctional sweat glands and high metabolic rate due to genetic selection for high performance (reviewed by Ross et al. [6]). Sows are more vulnerable to HS given the appropriate rearing temperature of approximate $20^{\circ} \mathrm{C}$. HS can potentially lead to abortion or early death in pregnant sows [7]. Early or late gestating sows exposed to HS produce fewer embryos that show lower survival as well as decreased litter sizes [8]. These results may be due to negative energy balance by low feed intake, which influence quality or development of oocyte, follicle and embryos by previous review [9]. In particular, pre- and postmating periods to sows are important because ovulation rates are positively affected in uterine viable embryos [10] and in both size and average weight of litter [11]. Furthermore, gastrointestinal microflora is affected by HS, which facilitates the growth of pathogenic bacteria due to damage of the intestinal epithelium [2]. Importantly, intestinal microbiota is associated with physiology and reproductive performance in prenatal sows [12].

Many researchers have investigated strategies for mitigating the negative effects of HS [13]. As a potential management strategy, cooling systems can be used to regulate the inner air temperature of feeding facilities [14]. Air cooling (AC) systems are most widely used in farms, while water-drip cooling (WC) systems are also widely used and effective in farrowing crates or individual stalls to cool sows given that they improving respiration rate, heart rate, and rectal and skin temperatures [15]. However, studies related to cooling facilities have largely been limited to sows housed under HS during gestation. Therefore, in the present study, early gestating sows exposed to hightemperature stress were investigated. Specifically, the effects of AC and WC on respiration rate, body temperature, blood metabolites, reproductive performance, and intestinal microflora were determined in these sows.

\section{MATERIALS AND METHODS}

\section{Cooling system preparation}

Cooling systems were prepared and applied in the gestating housing facility (individual stalls: $2.20 \times 0.65 \mathrm{~m}$ ) of National Institute of Animal Science (NIAS). An AC system comprising an air conditioner and duct was designed and installed to supply cold air above the head of sows in an individual stall. A WC system equipped with a water cooler and circulator was designed and installed to drop cold-water droplets (approximate $8^{\circ} \mathrm{C}$ ) on the cervical area of sows via adjustable flexible nozzles with a water-drip flow controlled at $20 \mathrm{~mL} / \mathrm{min}$. The AC and WC treatments were operated when the ambient temperature measured at shoulder height of the sows was $>27^{\circ} \mathrm{C}$. A treatment group exposed to HS without any cooling (denoted as the "HS" group) was used as a positive control; in this group, temperature was maintained at $\geq 30^{\circ} \mathrm{C}$ by a heater. The experimental facility was divided into three to avoiding interference effects among the treatment groups. Structural drawings of the AC and WC group set-ups are shown in Fig. 1.

\section{Experimental design and animals}

Thirty-nine sows (Landrace $\times$ Yorkshire) with two-parity were selected from the experimental farm of NIAS. These animals were randomly assigned to the three treatment groups as HS, AC, and WC and housed in individual stalls with 13 sows used per group. All sows were synchronized for 

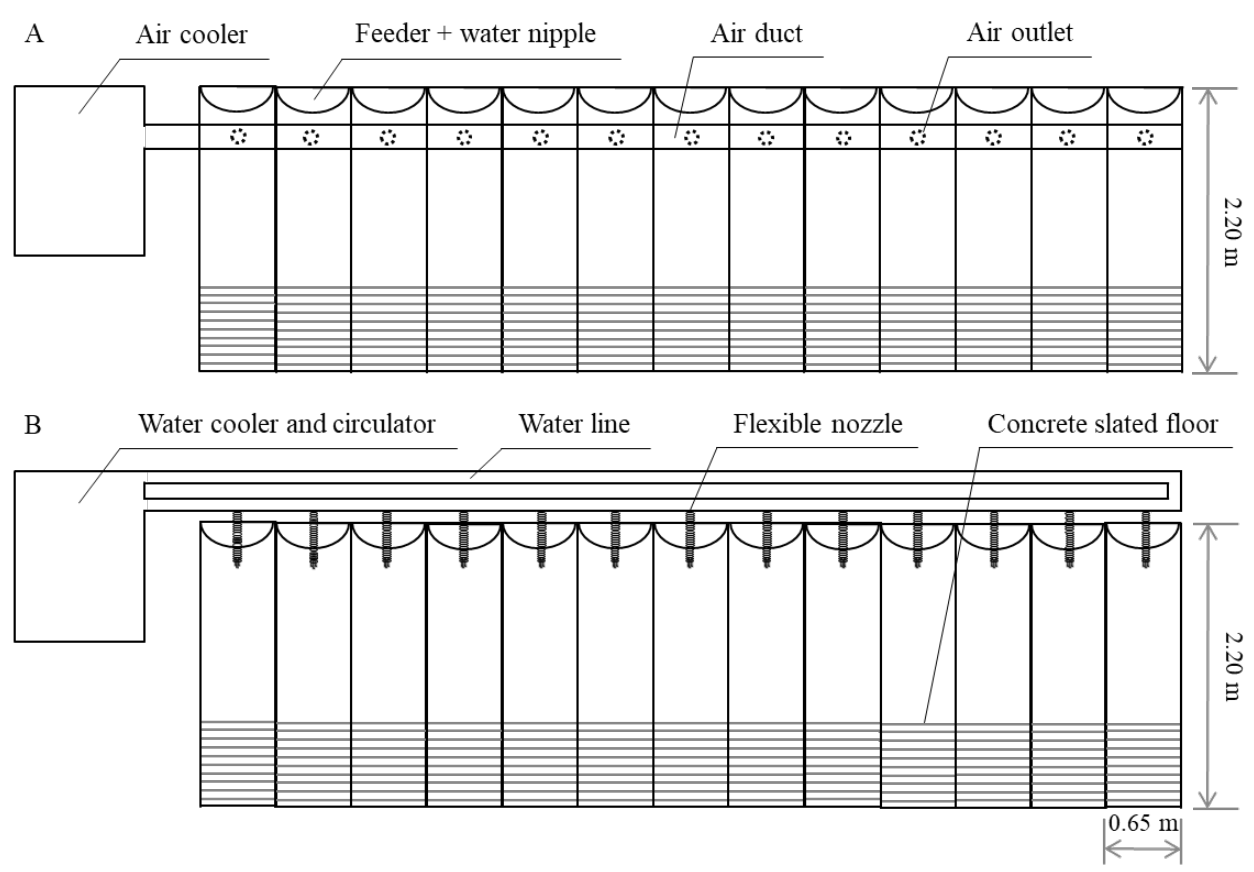

Fig. 1. Structural drawing of cooling systems used in this study. (A) Air cooling, (B) water-drip cooling. Sows were housed in individual stall $(2.2 \times 0.65 \mathrm{~m})$.

estrus using altrenogest (Regu-Mate; Intervet America, Inc., Millsboro, DE, USA) for 18 days and maintained at $\sim 25^{\circ} \mathrm{C}$. When the onset of estrus was observed, the sows were artificially inseminated twice and then each cooler was operated from mating to day 35 of the early gestation stage (which corresponded to the summer season from June 25, 2019, to August 29, 2019). An experimental diet was prepared as Table 1 . The allowance of the diet was $2.5 \mathrm{~kg} / \mathrm{d}$ from day 0 to day 90 of pregnancy and $2.8 \mathrm{~kg} / \mathrm{d}$ from day 91 to the farrowing days. For parturition, sows that had gestated for $104 \mathrm{~d}$ were transferred into farrowing crates. Also, water was freely accessed throughout the experimental period. The trial procedures were scrutinized and approved by the Institutional Animal Care and Use Committee of the NIAS (No. 2019-7131).

\section{Thermal conditions}

During the trial, dry bulb temperature $\left(\mathrm{T}_{\mathrm{ab}}\right)$ and relative humidity $(\mathrm{RH})$ were automatically recorded every 30 min using a data logger (174-H, Testo SE \& CO. KGaA, Lenzkirch, Germany), which was installed at the shoulder height of sows. The temperature-humidity index (THI) was identified by the equation from the NRC $[16]$ that THI $=\left(1.8 \times \mathrm{T}_{\mathrm{db}}+32\right)-[(0.55-0.0055 \times \mathrm{RH})$ $\left.\times\left(1.8 \times \mathrm{T}_{\mathrm{db}}-26.8\right)\right]$.

\section{Body responses}

Backfat thickness was measured at day 0 and day 35 of gestation at the P2 location, which is $6.5 \mathrm{~cm}$ to the right and left of the backbone at the tenth rib, using a ultrasonic imaging tester (Medicalexpo, Loveland, CO, USA). Rectal temperature was identified using a Testo 180 thermistor probe (Testo SE \& CO. KGaA). Skin temperature was visualized using a portable thermal imager (Testo 890, Testo SE \& CO. KGaA), which had an operating temperature range of $-15^{\circ} \mathrm{C}$ to $50^{\circ} \mathrm{C}$ with an accuracy of $\pm 2 \%$ and a resolution of $640 \times 480$ pixels for capturing images. These images were analyzed using IRSoft version 4.5 software (Testo SE \& CO. KGaA) to obtain 


\begin{tabular}{|c|c|}
\hline Ingredients & Percentage \\
\hline Corn & 65.79 \\
\hline Soybean meal & 15.00 \\
\hline Wheat & 6.00 \\
\hline Wheat bran & 2.09 \\
\hline Beet pulp & 5.00 \\
\hline Molasses & 2.00 \\
\hline Limestone & 0.89 \\
\hline Animal fat & 1.00 \\
\hline L-Lysine & 0.12 \\
\hline Mono-calcium phosphate & 1.31 \\
\hline Salt & 0.30 \\
\hline Mineral premix ${ }^{1)}$ & 0.25 \\
\hline Vitamin premix ${ }^{2)}$ & 0.25 \\
\hline \multicolumn{2}{|l|}{ Calculated compositions } \\
\hline ME (kcal/kg) & 3,300 \\
\hline $\mathrm{CP}(\%)$ & 14.47 \\
\hline $\mathrm{Ca}(\%)$ & 0.83 \\
\hline $\mathrm{P}(\%)$ & 0.62 \\
\hline Lysine (\%) & 0.80 \\
\hline Methionine (\%) & 0.23 \\
\hline \multicolumn{2}{|c|}{$\begin{array}{l}\text { 1)Provided the following quantities per } \mathrm{kg} \text { of complete diet: } \mathrm{Cu}, 87.5 \mathrm{mg} \text { as copper sulfate; } \mathrm{Fe}, 125 \mathrm{mg} \text { as iron sulfate; I, } 1.0 \mathrm{mg} \\
\text { as potassium iodate; } \mathrm{Mn}, 75 \mathrm{mg} \text { as manganese sulfate; } \mathrm{Se}, 0.25 \mathrm{mg} \text { as sodium selenite; and } \mathrm{Zn}, 60 \mathrm{mg} \text { as zinc oxide. } \\
\text { 2) Provided the following quantities per } \mathrm{kg} \text { of complete diet: vitamin } \mathrm{A}, 12,500 \mathrm{IU} \text {; vitamin } \mathrm{D} 3,1,000 \mathrm{IU} \text {; vitamin E, } 125 \mathrm{IU} \text {; vitamin } \\
\mathrm{K} 3,6.3 \mathrm{mg} \text {; thiamin, } 6.3 \mathrm{mg} \text {; riboflavin, } 25.0 \mathrm{mg} \text {; pyridoxine, } 12.5 \mathrm{mg} \text {; vitamin B12, } 0.1 \mathrm{mg} \text {; pantothenic acid, } 100 \mathrm{mg} \text {; folic acid, } \\
7.5 \mathrm{mg} \text {; niacin, } 225 \mathrm{mg} \text {; and biotin, } 0.5 \mathrm{mg} \text {. }\end{array}$} \\
\hline
\end{tabular}

average temperatures behind the ear, at the neck, and at the rump using a method of Rocha et al. [17]. Respiration rate was determined by counting the movements of the abdomen of sows during $1 \mathrm{~min}$. The temperatures and respiration rate were measured on the last day of the trial.

\section{Reproductive performance}

Pregnancy tests were conducted on day 35 of gestation using ultrasonography (AV 2100V, Ambisea Tech, Shenzhen, China). The fertility rate was calculated as the percentage of pregnant sows from the number of total mated sows. On the terminal day of the experiment, three gestating sows per group were randomly selected and euthanized according to the guidelines of the NIAS. Corpus lutea and embryos were counted at the uterus opening. The viable embryos were calculated by dividing the number of corpus lutea by the number of embryos. At farrowing, the piglet's total born, and those alive and dead, was identified. Mortality was calculated as the percentage of live animals from the total number of animals born per sow.

\section{Blood biochemical analysis}

On the terminating day of the experiment, blood ( $\mathrm{n}=8$ samples per group) was taken into serum tubes (SSTTM II advance, Becton Dickinson, Oxford, UK) from the jugular vein. For serum separation, the tube was centrifuged at $3,000 \times \mathrm{g}$ and $4^{\circ} \mathrm{C}$ for $20 \mathrm{~min}$. Serum aspartate aminotransferase (AST), alanine aminotransferase (ALT), total protein, blood urea nitrogen (BUN), and nonester fatty acids (NEFAs) were analyzed with a blood biochemical analyzer (ADVIA 120, 
Bayer,Leverkusen, Deutschland), and levels of thyroid hormones (T3 and T4) were measured using an electrochemiluminescent immunoassay method via a testing service from a clinical laboratory (Seegene Medical Foundation, Seoul, Korea).

\section{Gut microbiome analysis}

Before and after HS treatments, fresh feces were collected from five animals per group by rectal massage and then rapidly frozen in liquid nitrogen. The samples were maintained at $-80^{\circ} \mathrm{C}$ until further genomic DNA (gDNA) extraction. The gDNA from samples was extracted using $\mathrm{G}$-spin ${ }^{\mathrm{TM}}$ Genomic DNA Extraction Kit (iNtRON Biotechnology, Seongnam, Korea).

A $16 \mathrm{~S}$ rRNA sequencing targeting the V3 and V4 hypervariable regions were constructed according to a previous study [18]. The first PCR was performed using region-specific primers shown to have similarity with the Illumina index and sequencing adapters (forward primer:5'-TC GTCGGCAGCGTCAGATGTGTATAAGAGACAGCCTACGGGNGGCWGCAG-3'; reverse primer:5'-GTCTCGTGGGCTCGGAGATGTGTATAAGAGACAGGACTACHV GGGTATCTAATCC-3'). After magnetic bead-based purification of PCR products, a second PCR with limited cycles was performed using primers from a Nextera XT Index Kit (Illumina). The libraries were sequenced on the Miseq system (Illumina) with 300 bp paired-end reads. At the end of sequencing, the remaining reads were merged as paired-end reads using FLASH v 1.2.11. Merged reads containing more than two obscure nucleotides, those with a below of average score 20 (low-quality) or reads shorter than $300 \mathrm{bp}$, were filtered out. Potential chimeric sequences were detected using the Bellerophon method. The number of operational taxonomic units was calculated using the preprocessed reads from each sample and decided by clustering the sequences based on 97\% sequence identities using QIIME software (v.1.8.0). Taxonomic abundance was identified according to RDP Classifier v1.1 with 0.8 of a confidence threshold in preprocessed reads from each sample. The composition of microorganism was normalized to the count of taxonomic abundance. Alpha diversity of each sample was estimated by the Shannon index. As beta diversity, the difference in microorganism composition was identified by Bray-Curtis distance. Principal coordinate analysis $(\mathrm{PCoA})$ was then performed using the measured beta diversities.

\section{Statistical analysis}

Data were analyzed by using ANOVA or $t$-test of SPSS 20.0 (SPSS, Chicago, IL, USA). Animal was deemed as the experimental unit for reproductive performance, physiological parameters and microbial diversity. Statistical differences were determined with Turkey's multiple range tests among treatment groups, whereas, in taxonomic abundances, pre- and post-HS exposition in each group were conducted by independent-sample $t$-test. Differences were considered significant when $p$ was $<0.05$.

\section{RESULTS AND DISCUSSION}

\section{Thermal conditions}

The average temperature, $\mathrm{RH}$, and THI during the early gestation stage are shown in Table 2 . Average temperature and THI were highest in the HS group $\left(30.7^{\circ} \mathrm{C}\right.$ and 83.9 , respectively), but average $\mathrm{RH}$ was highest in the WC group (80.0\%). Variation in daily temperature, $\mathrm{RH}$, and THI during the experimental period is presented in Fig. 2. The daily temperature range in the HS and WC groups was $27.7^{\circ} \mathrm{C}-32.0^{\circ} \mathrm{C}$, whereas that in the $\mathrm{AC}$ group was $27.1^{\circ} \mathrm{C}-29.0^{\circ} \mathrm{C}$ for $9 \mathrm{~h}$ from $10: 30$ to $19: 30$ and $25.6^{\circ} \mathrm{C}-27^{\circ} \mathrm{C}$ for $15 \mathrm{~h}$ (i.e., the remaining time). The daily variation in $\mathrm{THI}$ in the $\mathrm{AC}$ group was 76.1-80.1, whereas that in the WC and $\mathrm{HS}$ groups was 79.6-82.9 
Table 2. Alteration of thermal conditions during experimental period

\begin{tabular}{lrrr}
\hline \multicolumn{1}{c}{ Items } & HS & AC & WC \\
\hline Temperature $\left({ }^{\circ} \mathrm{C}\right)$ & & & \\
Means & 30.72 & 26.87 & 28.81 \\
Maximum & 31.87 & 29.83 & 30.60 \\
Minimum & 29.02 & 24.19 & 27.19 \\
SD & 0.73 & 1.92 & 1.05 \\
Relative humidity (\%) & & & \\
Means & 78.91 & 78.95 & 80.03 \\
Maximum & 85.22 & 92.17 & 88.68 \\
Minimum & 70.24 & 68.59 & 73.15 \\
SD & 4.29 & 5.31 & 4.28 \\
THI & & & 81.05 \\
Means & 83.94 & 77.77 & 84.17 \\
Maximum & 86.40 & 82.08 & 77.73 \\
Minimum & 80.79 & 73.93 & 1.86 \\
SD & 1.45 & 2.95 & \\
\hline
\end{tabular}

HS, without any cooling; AC, air-cooling; WC, water-drip cooling; THI, temperature-humidity index.

A

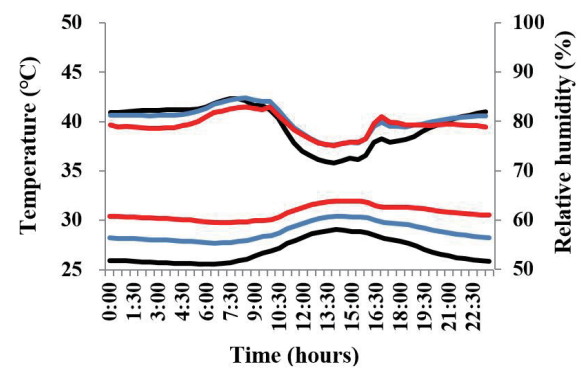

B

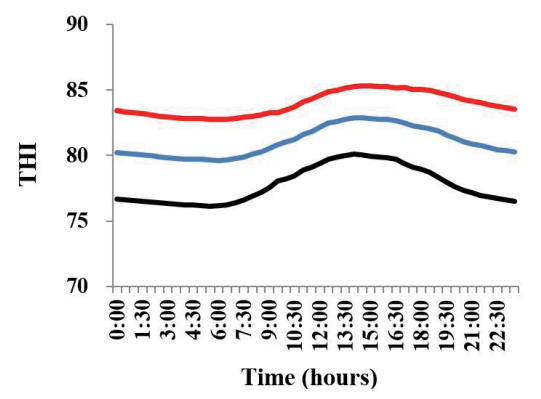

Fig. 2. Variation daily of thermal conditions during experimental period. Black line, air cooling; blue line, water-drip cooling; red line, heat stress without any cooling.

and 82.8-85.3, respectively. Temperature, $\mathrm{RH}$, and THI are used as indexes of thermal comfort in livestock. HS is mainly caused by high ambient temperature but its effect are strengthened by $\mathrm{RH}$ [19]. The THI is widely used as indicator by which to estimate HS. According to the classification of Haeussermann et al. [20], THI can be graded in degrees such as normal (below 75), alert (75 to 78), dangerous (79 to 83), and emergency (above 84). Thus, according to this classification, the AC and $\mathrm{WC}$ treatments in the present study mitigated the stress caused by high ambient temperature to some extent.

\section{Body responses}

Sows in the $\mathrm{AC}$ group showed significantly lower respiration rates and rectal temperatures than were shown by the HS group (36 vs. 102 breaths/min and $38.2^{\circ} \mathrm{C}$ vs. $38.5^{\circ} \mathrm{C}$, respectively; $p<$ 0.05; Table 3). Similarly, skin temperatures for the ear, neck, and rump areas were significantly lower in the AC group than they were in either the HS or WC groups $(p<0.05)$. In addition, the WC group had lower neck temperatures than those recorded in the $\mathrm{HS}$ group $\left(38.2^{\circ} \mathrm{C}\right.$ vs. $\left.38.9^{\circ} \mathrm{C} ; p<0.05\right)$. However, backfat thickness did not differ significantly among the groups at days 0 and 35 of the trial (data not shown). Previous researches are reported that hyperventilation and 
Table 3. Effect of cooling systems on respiration rate and body temperature in 35 days old gestating sows exposed to heat stress during early pregnant stage ${ }^{1)}$

\begin{tabular}{lcccc}
\multicolumn{1}{c}{ Items } & $\begin{array}{c}\text { HS } \\
(\mathbf{n = 1 3 )}\end{array}$ & $\begin{array}{c}\text { AC } \\
(\mathbf{n = 1 3 )}\end{array}$ & $\begin{array}{c}\text { WC } \\
(\mathbf{n}=13)\end{array}$ & SEM \\
\hline Respiration rate (breaths/min) & $102.08^{\mathrm{a}}$ & $35.54^{\mathrm{b}}$ & $98.38^{\mathrm{ab}}$ & 5.573 \\
Rectal temperature $\left({ }^{\circ} \mathrm{C}\right)$ & $38.53^{\mathrm{a}}$ & $38.23^{\mathrm{b}}$ & $38.33^{\mathrm{ab}}$ & 0.038 \\
Skin temperature $\left({ }^{\circ} \mathrm{C}\right)$ & & & \\
Ear & $38.77^{\mathrm{a}}$ & $35.00^{\mathrm{b}}$ & $38.60^{\mathrm{a}}$ & 0.306 \\
Neck & $38.98^{\mathrm{a}}$ & $33.81^{\mathrm{c}}$ & $38.18^{\mathrm{b}}$ & 0.381 \\
Rump & $38.82^{\mathrm{a}}$ & $35.03^{\mathrm{b}}$ & $38.77^{\mathrm{a}}$ & 0.299 \\
\hline
\end{tabular}

${ }^{1)}$ Animals were subjected to heat stress for early stage ( 0 to $35 \mathrm{~d}$ ) of gestation.

${ }^{a-c}$ Means with different superscript in same row differ below 0.05 of $p$-value.

HS, without any cooling; AC, air cooling system; WC, water-drip cooling system.

hyperthermia occur in pigs during heat waves. Heitman Jr et al. [7] reported a respiration rate of 157 breaths/min and rectal temperature of $40.6{ }^{\circ} \mathrm{C}$ in late pregnant sows kept with a maximum temperature of $35.8^{\circ} \mathrm{C}$. Lactating sows reared with $\mathrm{HS}$ at $32^{\circ} \mathrm{C}$ showed increased respiration rates and rectal temperatures compared with pigs reared under thermoneutral $(\mathrm{TN})$ conditions $\left(21^{\circ} \mathrm{C}\right)$ [21]. Similarly, Zhao et al. [22] reported lower respiration rates (23 vs. 101 breaths $/ \mathrm{min}$ ) and skin temperatures $\left(30.3^{\circ} \mathrm{C}\right.$ vs. $\left.36.6^{\circ} \mathrm{C}\right)$ in early-to-mid gestating sows kept at $\mathrm{TN}$ conditions of $20^{\circ} \mathrm{C}$ compared with sows subjected to cyclic $\mathrm{HS}$ at $28^{\circ} \mathrm{C}-33^{\circ} \mathrm{C}$. Another study reports lower respiration rate and temperature of ear and shoulder in pregnant sows under TN compared with HS [4]. These previous reports are similar to the results from the $\mathrm{AC}$ and $\mathrm{HC}$ groups in the present study. WC is often used in farrowing crates or individual stall to improve the respiration rate, heart rate, and rectal/skin temperatures of sows [23]. Murphy et al. [15] reported that the respiration rate was reduced by WC (63.6 vs. 28.5 breaths/min) in lactating sows housed with HS. Although there was no significant difference between the WC and HS groups in the current study, WC tended to improve the body responses of sows slightly. Furthermore, other cooling facilities as fogging, cooling pads and evaporative cooler show decrease of respiration rate and skin temperatures in lactating sows subjected to HS according to recent review [14]. Thus, the cooling systems seem to provide some thermal comfort to early gestating sows kept in high-temperature conditions.

\section{Blood metabolites}

The effect of the cooling systems on blood metabolites in early gestating sows exposed to high temperature are shown in Table 4. Total protein, ALT, AST, and NEFA in serum were not significantly affected by cooling systems. However, BUN was significantly increased in the WC group compared with its levels in the HS and AC groups $(p<0.05)$. In a previous study, growing pigs housed at $33^{\circ} \mathrm{C}$ showed decreased ALT or dynamic alteration of lipids in serum when compared with pigs housed at TN conditions of $23^{\circ} \mathrm{C}$, but total protein and BUN are not differed between the treatments [24]. Another study reported that absorptive metabolism for energy and nitrogen was reduced in gilt pigs exposed to cyclic or constant HS [25]. Sanz Fermandez et al. [26] reported that NEFA immediately increased in pigs under $\mathrm{HS}\left(31.6^{\circ} \mathrm{C}\right)$ and paired-fed TN (PFTN, $21^{\circ} \mathrm{C}$ ) conditions 1 day into a trial, before reaching a peak at 3 days, and then acutely decreasing; overall, however, pigs under HS showed 50\% lower NEFA . In contrast, there are not different to NEFA in growing pigs [3] and gestating sows [4]. Previous results for lipid metabolism suggest that it is differentially controlled according HS and TN conditions [24]. Therefore, given the range of results reported, further study is required to clarify the metabolic mechanisms underlying the effects of HS in pigs. In the present study, triiodothyronine (T3) was significantly higher in the AC 
Table 4. Effect of cooling systems on blood metabolites in 35 days old gestating sows exposed to heat stress during early pregnancy ${ }^{1)}$

\begin{tabular}{lcccc}
\hline \multicolumn{1}{c}{ Items } & $\begin{array}{c}\text { HS } \\
(\mathbf{n}=\mathbf{8})\end{array}$ & $\begin{array}{c}\text { AC } \\
(\mathbf{n}=\mathbf{8})\end{array}$ & $\begin{array}{c}\text { WC } \\
(\mathbf{n}=\mathbf{8})\end{array}$ & SEM \\
\hline Total protein (g/L) & 7.99 & 7.63 & 8.08 & 0.099 \\
BUN (mg/dL) & $8.00^{\mathrm{b}}$ & $7.25^{\mathrm{b}}$ & $10.25^{\mathrm{a}}$ & 0.430 \\
AST (U/L) & 161.75 & 110.25 & 141.75 & 32.423 \\
ALT (U/L) & 31.88 & 34.13 & 32.38 & 2.119 \\
NEFA (umol/L) & 65.75 & 64.13 & 65.50 & 13.089 \\
T3 (ng/dL) & $71.66^{\mathrm{b}}$ & $95.68^{\mathrm{a}}$ & $89.33^{\mathrm{ab}}$ & 4.703 \\
T4 (ug/dL) & 4.27 & 5.23 & 4.74 & 0.213 \\
\hline
\end{tabular}

${ }^{1)}$ Animals were subjected to heat stress for early stage ( 0 to $\left.35 \mathrm{~d}\right)$ of gestation.

${ }^{a, b}$ Means with different superscript in same row differ below 0.05 of $p$-value.

HS, without any cooling; AC, air cooling system; WC, water-drip cooling system; BUN, blood urea nitrogen; AST, aspartate aminotransferase; ALT, alanine aminotransferase; NEFA, non-ester fatty acids; T3, triiodothyronine; T4, thyroxine.

group than that in the HS group ( $p<0.05$; Table 4$)$, whereas thyroxine (T4) levels only slightly increased in the $\mathrm{AC}$ and $\mathrm{WC}$ groups compared to in the HS group. Thyroid hormones are known to stimulate heat production via energy and lipid metabolism [3,27]. Indeed, pigs exposed to HS show a remarkable reduction in the hormones required to ameliorate heat stroke according to previous study [28] and review [29].

\section{Reproductive performance}

The cooling treatments used in this study did not altered in the fertility of sows at day 35 of gestation (Table 5). Similarly, as reproductive parameters, the number of corpus lutea and embryos, along with embryo survival rate, did not differ significantly among the treatment groups. Thus, reproductive performance at farrowing was not affected by the cooling systems. Similarly, Liao and Veum [25] reported that subjecting pigs to cyclic or constant HS in early pregnancy does not influence the parameters tested in our study. In addition, sows housed under $\mathrm{TN}$ conditions $\left(20^{\circ} \mathrm{C}\right)$ rather than cyclic $\mathrm{HS}$ conditions $\left(28^{\circ} \mathrm{C}-33^{\circ} \mathrm{C}\right)$ during $40-60$ days of gestation were not affected in terms of corpus luteum number and embryo survival rate, but instead a numerical increase

Table 5. Effect of cooling systems on reproductive performance in gestating sows exposed to heat stress during early pregnant stage ${ }^{1)}$

\begin{tabular}{lcccc}
\hline \multicolumn{1}{c}{ Items } & \multicolumn{3}{c}{ Treatments } & \multirow{2}{*}{ SEM } \\
\cline { 2 - 4 } & HS & AC & WC & \\
\hline At the 35 d of gestation & & & & \\
$\quad$ Fertility (\%) & 84.62 & 76.92 & 84.62 & 6.225 \\
Corpus luteum/sow (no.) & 20.00 & 20.00 & 18.67 & 1.314 \\
Embryo/sow (no.) & 14.67 & 16.00 & 9.67 & 1.519 \\
Embryo/corpus luteum & 0.74 & 0.81 & 0.53 & 0.071 \\
At the farrowing & & & & \\
Total litter size (no.) & 15.14 & 14.86 & 11.88 & 0.748 \\
Alive born (no.) & 14.14 & 14.00 & 11.25 & 0.701 \\
Mortality (\%) & 6.41 & 5.04 & 5.42 & 1.550 \\
Birth weight (kg) & 1.52 & 1.39 & 1.57 & 0.044 \\
\hline
\end{tabular}

${ }^{1)}$ Animals were subjected to heat stress for early stage ( 0 to $\left.35 \mathrm{~d}\right)$ of gestation, whereas the other period was kept to below $24^{\circ} \mathrm{C}$ until parturition.

HS, without any cooling; AC, air cooling system; WC, water-drip cooling system. 
was observed in the TN group [22]. Omtvedt et al. [8] reported no effects on the performance of piglets produced from sows treated with HS during the mid gestating stage. However, HS is closely related to swine reproduction as it can (i) postpone the onset of puberty, (ii) compromise fertility, embryo development, and parturition rate, and (iii) reduce piglet performance [5,6,30]. This may be due to the insufficiency of the placenta according to results that show decreased placental nutrient transporter gene expression and epithelial layers [22]. Omtvedt et al. [8] also reported that HS at $32{ }^{\circ} \mathrm{C}-38^{\circ} \mathrm{C}$ during days $0-8$ or $8-16$ of gestation can, in fact, reduce the number of corpus lutea and viable embryos in sows. In addition, these authors reported reduced litter performance in sows housed with HS during days 102-110 of gestation. The contrary results in these reports may have arisen for two reasons. First, HS sensitivity may differ according to pregnancy stage, i.e., early or late gestation are important periods because of embryo implantation and acute fetus growth. Second, genetic potential may be a factor; global breeding strategies typically focus on economically efficient selection, which can affect heat production due to increased physiological demand as the reproductive and lean growth cycle are accelerated in selected swine [6,31].

\section{Gut microbiome}

In the current study, the Shannon index was slightly decreased after HS relative to the value before HS (Fig. 3). Similarly, a significant decrease was observed in the index after HS compared with the index before HS with WC (5.2 vs. 5.6; $p<0.05$ ). According to taxonomic classification, however, microbial diversity at the phylum level was not changed by HS and cooling (Table 6). In contrast, after HS with AC and WC, microbial diversity at the family and genus levels was greater than before HS and before HS with AC ( $p<0.05)$, but it did not differ simply before and after HS. At the species levels, after HS with AC or WC, microbial diversity was higher than before HS, after HS, and before HS with $\mathrm{AC}(p<0.05)$. Intestinal microbes are closely related to the health of the host and play an essential role in the digestion and absorption of nutrients as well as in the development of immunity [24]. Indeed, balanced intestinal microflora can have beneficial effects on gut health by preventing the invasion of pathogenic bacteria and enhancing the function of the intestinal barrier [32]. In particular, increasing the diversity of intestinal microbes has a significant

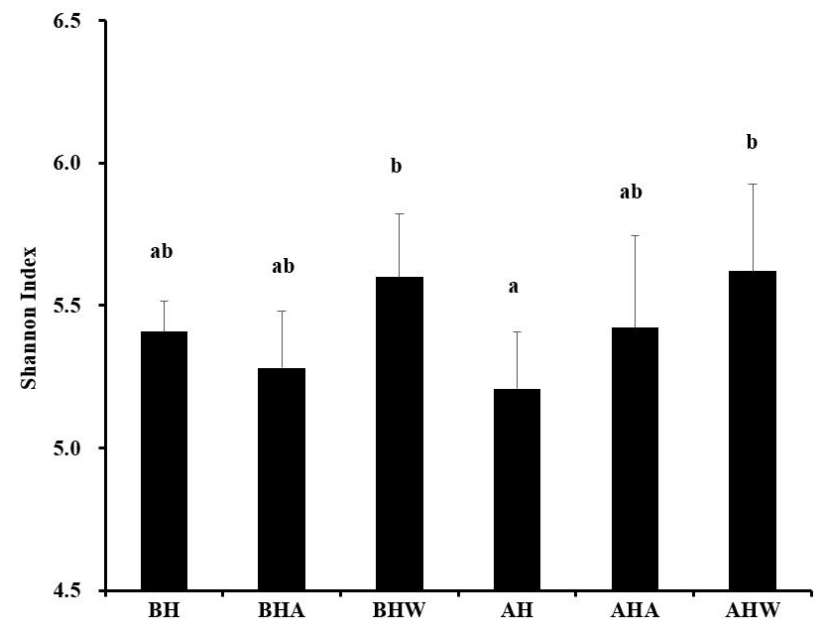

Fig. 3. Shannon index on microbial diversity in early gestating sows housed to cooling systems before or after high temperature stress. Animals were subjected to heat stress during early stage ( 0 to $35 \mathrm{~d})$ of gestation. ${ }^{\mathrm{a}, \mathrm{b}}$ Means are significantly different within the same row $(p<0.05)$. $\mathrm{BH}$, before heat stress; $\mathrm{BHA}$, before heat stress + air cooling; BHW, before heat stress + water-drip cooling; $\mathrm{AH}$, after heat stress; AHA, after heat stress + air cooling; AHW, after heat stress + water-drip cooling. 
Table 6. Taxonomic classification on microbial diversity in early gestating sows housed to cooling systems before or after high stress ${ }^{1)}$

\begin{tabular}{|c|c|c|c|c|c|c|c|}
\hline \multirow[b]{2}{*}{ Items } & \multicolumn{3}{|c|}{ Before heat stress } & \multicolumn{3}{|c|}{ After heat stress } & \multirow[b]{2}{*}{ SEM } \\
\hline & $\begin{array}{c}\text { HS } \\
(n=5)\end{array}$ & $\begin{array}{c}A C \\
(n=5)\end{array}$ & $\begin{array}{c}\text { WC } \\
(n=5)\end{array}$ & $\begin{array}{c}\text { HS } \\
(n=5)\end{array}$ & $\begin{array}{c}A C \\
(n=5)\end{array}$ & $\begin{array}{c}\text { WC } \\
(n=5)\end{array}$ & \\
\hline Phylum & 15.80 & 16.00 & 17.80 & 16.80 & 17.20 & 18.20 & 0.344 \\
\hline Family & $99.60^{c}$ & $99.40^{c}$ & $106.40^{\mathrm{bc}}$ & $105.00^{\mathrm{bc}}$ & $117.00^{\mathrm{ab}}$ & $127.20^{\mathrm{a}}$ & 2.727 \\
\hline Genus & $273.60^{c}$ & $271.80^{c}$ & $295.40^{\mathrm{abc}}$ & $281.40^{\mathrm{bc}}$ & $322.80^{\mathrm{ab}}$ & $334.40^{\mathrm{a}}$ & 7.027 \\
\hline Species & $509.80^{b}$ & $508.80^{b}$ & $546.60^{\mathrm{ab}}$ & $523.20^{\mathrm{b}}$ & $596.80^{a}$ & $616.80^{a}$ & 11.710 \\
\hline
\end{tabular}

${ }^{1)}$ Animals were subjected to heat stress for early stage ( 0 to $35 \mathrm{~d}$ ) of gestation.

${ }^{a-c}$ Means are significantly different within the same row $(p<0.05)$.

HS, without any cooling; AC, air cooling system; WC, water-drip cooling system.

effect on host physiology and immune response [33], whereas decreasing diversity can lead to digestive disease [34]. Thus, according the present results, cooling systems can positively alter the diversity of intestinal microorganisms in sows housed under HS conditions.

The overall structural changes in intestinal microbiota were analyzed using PCoA (Fig. 4). The PCoA plots for microbial communities before and after HS indicated that high-temperature conditions altered the intestinal microflora of sows. Specifically, after HS, patterns in the intestinal microbial community differed between the HS and WC groups. However, the intestinal microbial community in pigs from the AC group resembled those of the $\mathrm{HS}$ and $\mathrm{WC}$ groups. Certain PCoA plots in the WC group were also apparent in sows before HS, which may have arisen due to differences among sows rather than because of HS-related changes in intestinal microbial. As HS seemed to change the microbial community in the gut of sows, we further investigated the changes in microbial species.

Specific HS-induced changes in intestinal microflora were identified in pregnant sows (Fig. 5): the distribution of intestinal microorganisms at the phylum level (Fig. 5A) and the proportion

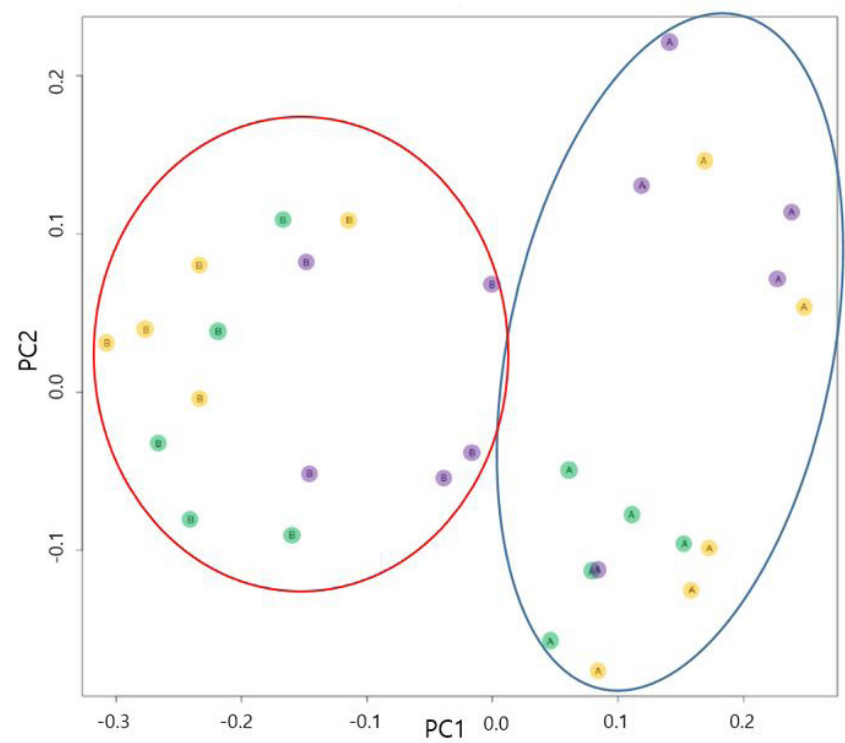

Fig. 4. Principal coordinate analysis (PCoA) of community strectures using a fast unifrac distance matrix in early gestating sows housed to cooling systems before or after high temperature stress. Animals were undergone to heat stress during early stage ( 0 to $35 \mathrm{~d}$ ) of gestation. PC1, principal component 1 ; PC2, principal component 2; red circle, before heat stress; blue circle, after heat stress; green dot, without any cooling; yellow dot, air cooling; purple dot, water-drip cooling. 
A

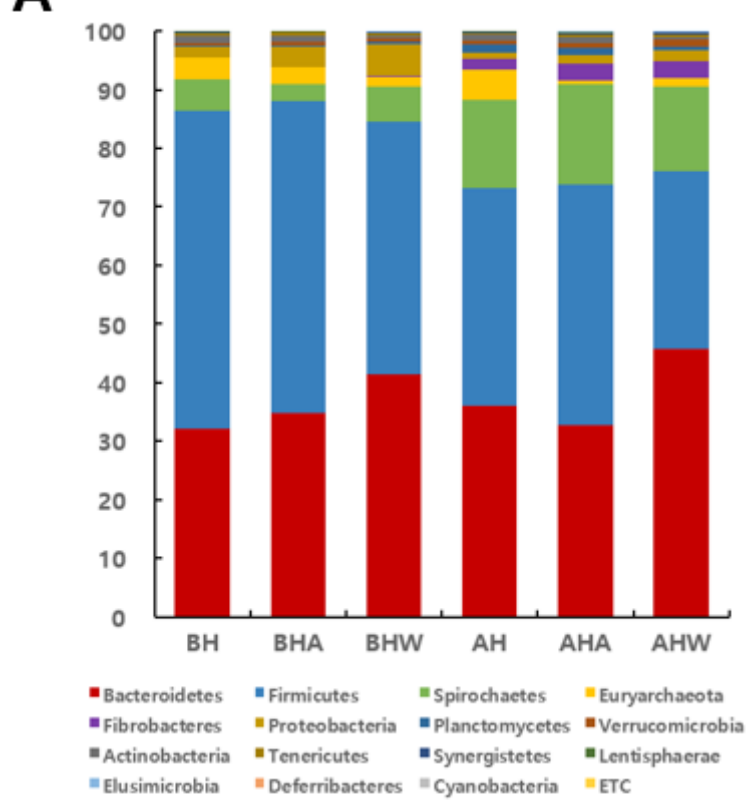

C

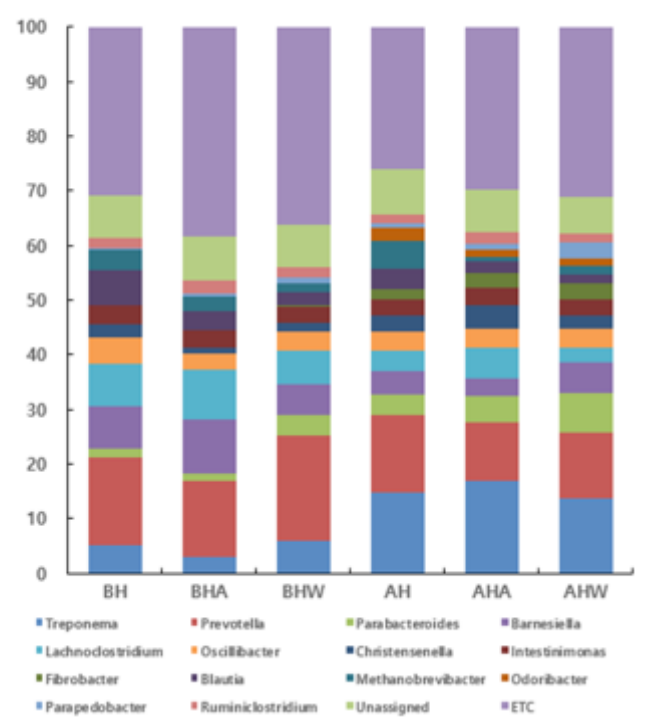

B
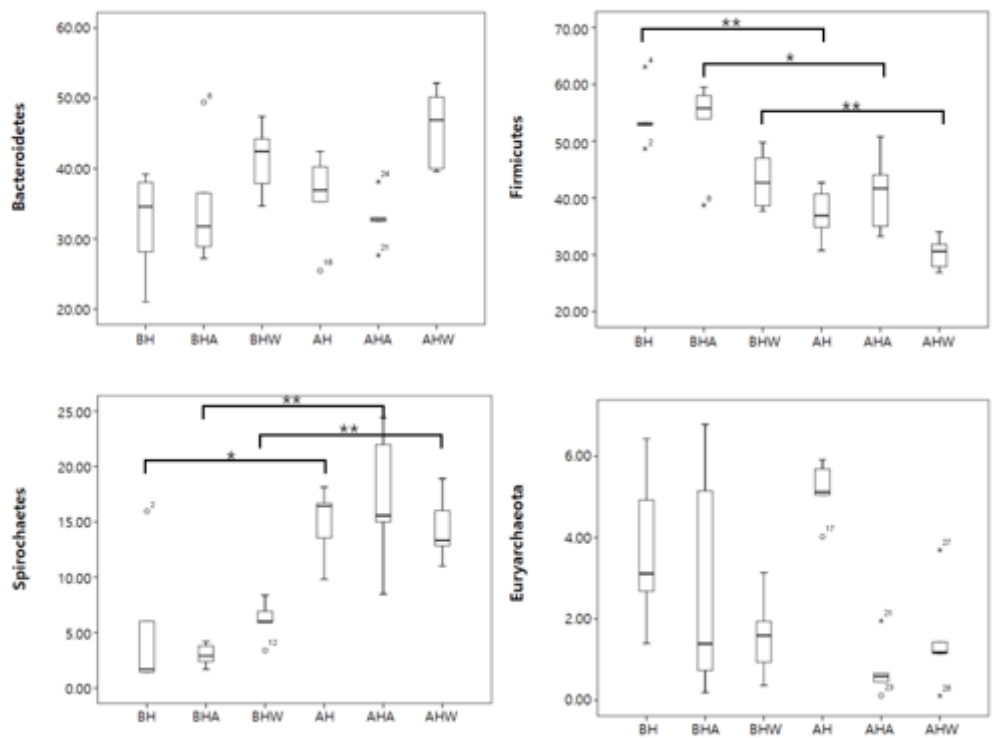

D
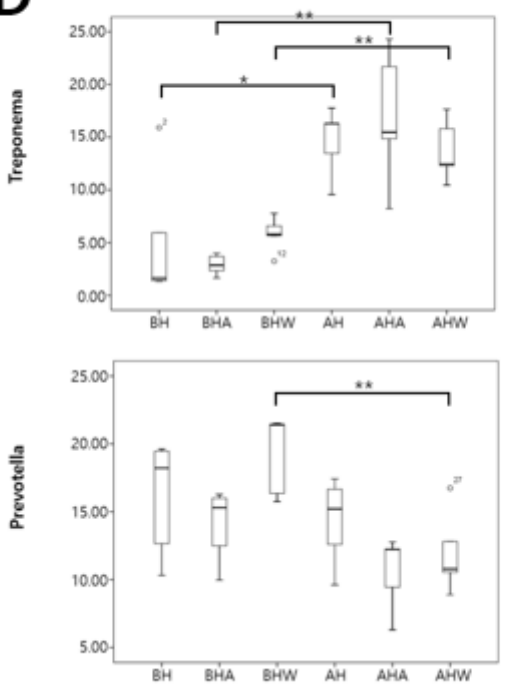

Fig. 5. Microbial diversity on the phylum and genus levels in early gestating sows housed to cooling systems before or after high-temperature stress. (A, B) Composition of fecal microbiota at the phylum level, (C, D) Composition of fecal microbiota at the genus level. Animals were undergone to heat stress during early stage ( 0 to $35 \mathrm{~d}$ ) of gestation. ${ }^{*} p<0.05,{ }^{* *} p<0.01$; versus the before heat stress. $\mathrm{BH}$, before heat stress; $\mathrm{BHA}$, before heat stress + air cooling; BHW, before heat stress + water-drip cooling; AH, after heat stress; AHA, after heat stress + air cooling; AHW, after heat stress + water-drip cooling group.

of different species in the intestinal microflora of pigs (Fig. 5B) were altered after HS. Levels of Bacteroidetes were not altered by HS, but those of Firmicutes decreased significantly after HS (54.15\% of all phyla before HS vs. $37.16 \%$ after HS; $p<0.01$ ). Compared with levels before HS, the AC and WC groups also showed significantly decreased proportions of Firmicutes after HS ( $p$ $<0.05$ and $p<0.01$, respectively). Levels of the harmful intestinal bacteria Spirochaetes increased significantly in all groups subjected to HS $(p<0.05)$. At the genus level (Fig. 5C), Treponema, a pathogenic microorganism, comprised $2.37 \%$ of the detected genera before HS but increased significantly to comprise $14.68 \%$ of the detected genera after HS $(p<0.05)$. Similarly, the AC 
and WC groups showed a significant increase in Treponema after HS $(p<0.01)$. Another common genus, Prevotella was not affected by HS in sows nor by HS in the AC group; however, levels of Prevotella significantly decreased $(p<0.01)$ in the WC group. Notably, since the proportion of Prevotella did not differ significantly among groups after HS, it is presumed that Prevotella was more prevalent in groups other than WC before HS and that HS did not affect this genus.

Firmicutes and Bacteroidetes are known to be dominant in the intestinal microflora of pigs and, phylogenetically, account for $>90 \%$ of the intestinal microflora in humans and mice [35]. In the present study, Firmicutes and Bacteroidetes were also dominant at the phylum level in sows. After Firmicutes and Bacteroidetes, the most dominant phylum was Spirochaetes, which increased in all groups subjected to HS. Spirochaetes found in pig intestines have long been recognized as diseasecausing pathogens in humans and birds [36]. Euryarchaeota, another potentially harmful bacteria found in the intestines [37], was significantly reduced in the AC and WC groups compared with in the HS group. At the genus level, Prevotella species were dominant in the tested sows. Prevotella is commonly found in species that consume fiber diets [38] and is known to contribute to the breakdown of carbohydrates [39]. Also at the genus level, Treponema species increased to the greatest extent in the intestinal microflora of sows after HS. Treponema contains many species of pathogenic microorganisms [39]. Indeed, this genus is associated with various tumor system diseases related to syphilis in humans and dermatitis in cattle [40], and is known to cause dysentery in pigs [41]. In the current study, following HS, Treponema increased by $12 \%$ and $14 \%$ in the HS and $\mathrm{AC}$ groups, respectively, but increased by only $8 \%$ the WC group. In addition, the respiratory rate of sows was significantly reduced in the AC group, which may have had a minimal effect on intestinal microbial changes caused by heat shock. This is because the THI in the AC group was at a warning-risk level for 4 weeks and was only normal in the last week, which indicates that the recovery period was insufficient to restore the intestinal environment of sows exposed to HS. In comparison, the intestinal environment was not restored to normal levels (i.e., those before HS) in the WC group, although levels were still improved in relation to those in the HS group.

\section{CONCLUSION}

The swine industry is suffering substantial economic expenditure due to HS-related issues. Thus, using cooling systems on gestating sows with HS was evaluated here by measuring variables such as body (rectum and skin) temperature, respiration rate, thyroid hormone levels, reproductive performance, and the gut microbiome. Taken together, our results indicate that the AC treatment stabilized the biometric cycle of early pregnant sows exposed to HS but did not affect reproductive performance. In addition, the impact of $\mathrm{HS}$ on the diversity of gut microbiome was minimized by the use of cooling systems. Overall, our data suggest that $\mathrm{AC}$ or WC could ameliorate or mitigate, to some extent, the adverse effects of $\mathrm{HS}$ on various physiological parameters and the intestinal microbes of pregnant sows. However, current study may lack representation owing to relatively less animal number used. Therefore, further study can be needed to reevaluate effect of cooling system by using large scale or farm unit.

\section{REFERENCES}

1. Baumgard LH, Rhoads RP Jr. Effects of heat stress on postabsorptive metabolism and energetics. Annu Rev Anim Biosci. 2013;1:311-37. https://doi.org/10.1146/annurev-animal-031412-103644

2. Sanz Fernandez MV, Pearce SC, Mani V, Gabler NK, Metzger L, Patience JF, et al. Effects 
of dairy products on intestinal integrity in heat-stressed pigs. Temperature. 2014;1:128-34. https://doi.org/10.4161/temp.29561

3. Pearce SC, Gabler NK, Ross JW, Escobar J, Patience JF, Rhoads RP, et al. The effects of heat stress and plane of nutrition on metabolism in growing pigs. J Anim Sci. 2013;91:2108-18. https://doi.org/10.2527/jas.2012-5738

4. Maskal JM, Duttlinger AW, Kpodo KR, McConn BR, Byrd CJ, Richert BT, et al. Evaluation and mitigation of the effects of in utero heat stress on piglet growth performance, postabsorptive metabolism, and stress response following weaning and transport. J Anim Sci. 2020;98:113. https://doi.org/10.1093/jas/skaa265

5. Johnson JS, Stewart KR, Safranski TJ, Ross JW, Baumgard LH. In utero heat stress alters postnatal phenotypes in swine. Theriogenology. 2020;154:110-9. https://doi.org/10.1016/j.theriogenology.2020.05.013

6. Ross JW, Hale BJ, Seibert JT, Romoser MR, Adur MK, Keating AF, et al. Physiological mechanisms through which heat stress compromises reproduction in pigs. Mol Reprod Dev. 2017;84:934-45. https://doi.org/10.1002/mrd.22859

7. Heitman Jr H, Hughes EH, Kelly CF. Effects of elevated ambient temperature on pregnant sows.J Anim Sci. 1951;10:907-15. https://doi.org/10.2527/jas1951.104907x

8. Omtvedt IT, Nelson RE, Edwards RL, Stephens DF, Turman EJ. Influence of heat stress during early, mid and late pregnancy of gilts. J Anim Sci. 1971;32:312-7. https://doi. org/10.2527/jas1971.322312x

9. Peltoniemi O, Yun J, Björkman S, Han T. Coping with large litters: the management of neonatal piglets and sow reproduction. J Anim Sci Technol. 2021;63:1-15. https://doi.org/10.5187/ jast.2021.e3

10. Da Silva CLA, Van Den Brand H, Laurenssen BFA, Broekhuijse MLWJ, Knol EF, Kemp $\mathrm{B}$, et al. Relationships between ovulation rate and embryonic and placental characteristics in multiparous sows at 35 days of pregnancy. Animal. 2016;10:1192-9. https://doi.org/10.1017/ S175173111600015X

11. Foxcroft GR, Dixon WT, Novak S, Putman CT, Town SC, Vinsky MDA. The biological basis for prenatal programming of postnatal performance in pigs. J Anim Sci. 2006;84:E105-12. https://doi.org/10.2527/2006.8413_supplE105x

12. Shao Y, Zhou J, Xiong X, Zou L, Kong X, Tan B, et al. Differences in gut microbial and serum biochemical indices between sows with different productive capacities during perinatal period. Front Microbiol. 2020;10:3047. https://doi.org/10.3389/fmicb.2019.03047

13. Johnson JS. Heat stress: impact on livestock well-being and productivity and mitigation strategies to alleviate the negative effects. Anim Prod Sci. 2018;58:1404-13. https://doi. org/10.1071/AN17725

14. Godyń D, Herbut P, Angrecka S, Corrêa Vieira FM. Use of different cooling methods in pig facilities to Alleviate the effects of heat stress-a review. Animals. 2020;10:1459. https://doi. org/10.3390/ani10091459

15. Murphy JP, Nichols DA, Robbins FV. Drip cooling of lactating sows. Appl Engin Agric. 1987;3:200-2. https://doi.org/10.13031/2013.26673

16. NRC [National Research Council]. A guide to environmental research on animals. Washington, DC: National Academies Science; 1971.

17. Rocha LM, Devillers N, Maldague X, Kabemba FZ, Fleuret J, Guay F, et al. Validation of anatomical sites for the measurement of infrared body surface temperature variation in response to handling and transport. Animals. 2019;9:425. https://doi.org/10.3390/ani9070425

18. Klindworth A, Pruesse E, Schweer T, Peplies J, Quast C, Horn M, et al. Evaluation of general 
16S ribosomal RNA gene PCR primers for classical and next-generation sequencing-based diversity studies. Nucleic Acids Res. 2013;41:e1. https://doi.org/10.1093/nar/gks808

19. Jeelani R, Konwar D, Khan A, Kumar D, Chakraborty D, Brahma B. Reassessment of temperature-humidity index for measuring heat stress in crossbred dairy cattle of a sub-tropical region.J Therm Biol. 2019;82:99-106. https://doi.org/10.1016/j.jtherbio.2019.03.017

20. Haeussermann A, Vranken E, Aerts JM, Hartung E, Jungbluth T, Berckmans D. Evaluation of control strategies for fogging systems in pig facilities. Trans ASABE. 2007;50:265-74. https:// doi.org/10.13031/2013.22407

21. Spencer JD, Boyd RD, Cabrera R, Allee GL. Early weaning to reduce tissue mobilization in lactating sows and milk supplementation to enhance pig weaning weight during extreme heat stress.J Anim Sci. 2003;81:2041-52. https://doi.org/10.2527/2003.8182041x

22. Zhao W, Liu F, Bell AW, Le HH, Cottrell JJ, Leury BJ, et al. Controlled elevated temperatures during early-mid gestation cause placental insufficiency and implications for fetal growth in pregnant pigs. Sci Rep. 2020;10:20677. https://doi.org/10.1038/s41598-020-77647-1

23. Barbari M, Conti L. Use of different cooling systems by pregnant sows in experimental pen. Biosyst Eng. 2009;103:239-44. https://doi.org/10.1016/j.biosystemseng.2009.02.016

24. Wen X, Wu W, Fang W, Tang S, Xin H, Xie J, et al. Effects of long-term heat exposure on cholesterol metabolism and immune responses in growing pigs. Livest Sci. 2019;230:103857. https://doi.org/10.1016/j.livsci.2019.103857

25. Liao CW, Veum TL. Effects of dietary energy intake by gilts and heat stress from days 3 to 24 or 30 after mating on embryo survival and nitrogen and energy balance. J Anim Sci. 1994;72:2369-77. https://doi.org/10.2527/1994.7292369x

26. Sanz Fernandez MV, Stoakes SK, Abuajamieh M, Seibert JT, Johnson JS, Horst EA, et al. Heat stress increases insulin sensitivity in pigs. Physiol Rep. 2015;3:e12478. https://doi. org/10.14814/phy2.12478

27. Pucci E, Chiovato L, Pinchera A. Thyroid and lipid metabolism. Int J Obes. 2000;24:S109-12. https://doi.org/10.1038/sj.ijo.0801292

28. Sanz Fernandez MV, Johnson JS, Abuajamieh M, Stoakes SK, Seibert JT, Cox L, et al. Effects of heat stress on carbohydrate and lipid metabolism in growing pigs. Physiol Rep. 2015;3:e12315. https://doi.org/10.14814/phy2.12315

29. Gonzalez-Rivas PA, Chauhan SS, Ha M, Fegan N, Dunshea FR, Warner RD. Effects of heat stress on animal physiology, metabolism, and meat quality: a review. Meat Sci. 2020;162:108025. https://doi.org/10.1016/j.meatsci.2019.108025

30. Wegner K, Lambertz C, Daş G, Reiner G, Gauly M. Climatic effects on sow fertility and piglet survival under influence of a moderate climate. Animal. 2014;8:1526-33. https://doi. org/10.1017/S1751731114001219

31. Prunier A, Heinonen M, Quesnel H. High physiological demands in intensively raised pigs: impact on health and welfare. Animal. 2010;4:886-98. https://doi.org/10.1017/ S175173111000008X

32. He J, He Y, Pan D, Cao J, Sun Y, Zeng X. Associations of gut microbiota with heat stress-induced changes of growth, fat deposition, intestinal morphology, and antioxidant capacity in ducks. Front Microbiol. 2019;10:903. https://doi.org/10.3389/fmicb.2019.00903

33. Carrera-Quintanar L, López Roa RI, Quintero-Fabián S, Sánchez-Sánchez MA, Vizmanos B, Ortuño-Sahagún D. Phytochemicals that influence gut microbiota as prophylactics and for the treatment of obesity and inflammatory diseases. Mediators Inflamm. 2018;2018:9734845. https://doi.org/10.1155/2018/9734845

34. Gresse R, Chaucheyras-Durand F, Fleury MA, Van de Wiele T, Forano E, Blanquet-Diot S. 
Gut microbiota dysbiosis in postweaning piglets: understanding the keys to health. Trends Microbiol. 2017;25:851-73. https://doi.org/10.1016/j.tim.2017.05.004

35. Cui C, Shen CJ, Jia G, Wang KN. Effect of dietary Bacillus subtilis on proportion of Bacteroidetes and Firmicutes in swine intestine and lipid metabolism. Genet Mol Res. 2013;12:176676. https://doi.org/10.4238/2013.May.23.1

36. Hampson DJ, Ahmed N. Spirochaetes as intestinal pathogens: lessons from a Brachyspira genome. Gut Pathog. 2009;1:10. https://doi.org/10.1186/1757-4749-1-10

37. Li Y, Wang P, Yin J, Jin S, Su W, Tian J, et al. Effects of ornithine $\alpha$-ketoglutarate on growth performance and gut microbiota in a chronic oxidative stress pig model induced by $\mathrm{d}$-galactose. Food Funct. 2020;11:472-82. https://doi.org/10.1039/C9FO02043H

38. González-Prendes R, Pena RN, Solé E, Seradj AR, Estany J, Ramayo-Caldas Y. Modulatory effect of protein and carotene dietary levels on pig gut microbiota. Sci Rep. 2019;9:14582. https://doi.org/10.1038/s41598-019-51136-6

39. Tan Z, Wang Y, Yang T, Ao H, Chen S, Xing K, et al. Differences in gut microbiota composition in finishing Landrace pigs with low and high feed conversion ratios. Antonie Van Leeuwenhoek. 2018;111:1673-85. https://doi.org/10.1007/s10482-018-1057-1

40. Evans NJ, Brown JM, Murray RD, Getty B, Birtles RJ, Hart CA, et al. Characterization of novel bovine gastrointestinal tract Treponema isolates and comparison with bovine digital dermatitis treponemes. Appl Environ Microbiol. 2011;77:138-47. https://doi.org/10.1128/ AEM.00993-10

41. Schmall LM, Argenzio RA, Whipp SC. Pathophysiologic features of swine dysentery: cyclic nucleotide-independent production of diarrhea. Am J Vet Res.1983;44:1309-16. 